\title{
Contribuições do design no ensino: animação em Stop Motion
}

\author{
Contributions of design in teaching: animation in stop motion
}

OURIVES, Eliete Auxiliadora Assunção; Pós-doutora; Universidade Federal de Santa Catarina LABDesign

elieteourives@gmail.com

FIGUEIREDO, Luiz Fernando Gonçalves de; Pós-doutor; Universidade Federal de Santa Catarina NASDesign

Iffigueiredo2009@gmail.com

VIEIRA, Milton Luiz Horn - Pós-doutor; Universidade Federal de Santa Catarina - LABDesign

milton@cce.ufsc.br

ANDRADE, Willian; Doutor; Universidade Federal de Santa Catarina - LABDesign

Willian.ufsc.@gmail.com

CESTARI, Glauba Alves do Vale; Doutoranda; Universidade Federal de Santa Catarina

glauba.cestari@ifma.edu.br

CONTI, Paolo; Mestrando; Universidade Federal de Santa Catarina - Animaking

paolo@animaking.com.br

MACEDO, Thales Eduardo; Graduado; Universidade Federal de Santa Catarina - Animaking

Thales@animaking.com.br

\section{Resumo}

O Stop Motion é uma técnica de animação que simula o movimento parado de um objeto inanimado, utilizando a disposição sequencial de fotografias. A sua aplicação no ensino pode contribuir para facilitar a memorização de conteúdo, envolver e motivar o aprendiz, podendo ser empregada no âmbito escolar, trazendo mudanças de paradigma aos processos de ensino e aprendizagem tradicionais. Dessa forma, o presente trabalho teve por objetivo, realizar, levantamento bibliográfico acerca da utilização da técnica de animação em stop motion como ferramenta no ensino e também entrevistar o professor orientador (viabilizador) da disciplina de na IES, para replicar no ensino fundamental e médio, em escolas públicas e privadas. O design contribui na idealização, criação, concepção de artefatos no processo de produção da animação. Por fim, esta pesquisa de abordagem qualitativa e exploratória, apresenta algumas diretrizes, no intuito de incentivar novos estudos e a aplicabilidade desta prática na educação.

Palavras Chave: animação; stop motion; ensino; aprendizagem.

\footnotetext{
Abstract

Stop Motion is an animation technique that simulates the still motion of an inanimate object using the sequential arrangement of photographs. Its application in teaching can contribute to facilitate the memorization of content, involve and motivate the learner, and can be used in the school environment, bringing paradigm shifts to traditional teaching and learning processes. The aim of this study was to carry out a bibliographical survey about the use of the stop motion animation technique as a tool in teaching and also to interview the instructor teacher (viabilizer) of the
} 
discipline of sotp motion in the IES, to replicate in elementary education and middle schools in public and private schools. The design contributes to idealization, creation, and design of artifacts in the production process of animation. Finally, this research with a qualitative and exploratory approach, presents some guidelines, in order to encourage new studies and the applicability of this practice in education.

Keywords: animation; stop motion; teaching; learning.

\section{Introdução}

O design é uma atividade orientada pelo objetivo de atender demandas ou solucionar problemas, mediante métodos que envolvem idealização, criação, concepção de artefatos ou serviços. A animação, entre outras formas de atuação, é uma área que planeja e executa projetos de animação, mediante técnicas e ferramentas. Dentre as técnicas de animação existentes, destacase, neste estudo, a animação denominada como stop motion. Essa, vem sendo cada vez mais explorada na área da educação com o objetivo de beneficiar o processo de educação em todos os seus níveis, formas e modalidades apresentando-se como estratégia pedagógica ao docente para motivar os discentes, mediante uma forma inovadora e eficaz de transmissão de conteúdo.

A técnica de animação em stop motion ao longo dos anos vem armazenando um significativo acervo de propostas para o trabalho em sala de aula, que podem colaborar para melhorias importantes na formação discente. Assim, é importante conhecer tais propostas, saber avaliá-las e adequá-las, contribuindo para uma aprendizagem mais significativa. É o que se pretende neste trabalho. Assim, por um viés analítico, pesquisou-se sobre a técnica de animação em stop motion e a relação com iniciativas pedagógicas, tendo em vista o uso dessa, como ferramenta no processo de ensino e aprendizagem. Este estudo apresenta iniciativas de pesquisas que pretendiam sair do convencional buscando o envolvimento e a participação efetiva de alunos na construção do conhecimento, mediante atividades práticas em escolas públicas e particulares do ensino fundamental e médio, despertando o interesse desses alunos para o conteúdo curricular, assim como para os temas de cinema e animação.

Acredita-se que ações voltadas à educação escolar podem motivar alunos da graduação em animação e design, principalmente aqueles de iniciação científica, e também da pós-graduação, a divulgarem seus trabalhos de pesquisa de modo simples e com linguagem adequada ao público pretendido, oportunidade que se constitui numa contribuição importante aos universitários, despertando-os, inclusive, para a importância da docência, da sua formação profissional, assim como, das possíveis contribuições advindas da academia e do mercado para a inovação e desenvolvimento dos processos educacionais. Nessa concepção, o aluno do ensino fundamental e médio é o centro da aprendizagem e os esforços dos seus professores não devem exceder o limite de um agente viabilizador, sem eximi-los de propiciar as informações e os procedimentos necessários para despertar a motivação dos alunos.

Portanto, ao considerar os trabalhos pesquisados, observa-se a possibilidade de modificar o ambiente de aprendizado do aluno, o qual pode ser trazido da sala de aula convencional para um espaço de pesquisa gerador de novos conhecimentos, interlocuções e interações nos diferentes níveis da educação. Com isso, vislumbra-se o despertar de reflexões sobre a importância sociocultural do curso de animação ao contribuir para a educação por meio dos métodos aplicados na produção de animações em atividades de ensino que visam o entendimento e exposição de um 
dado conteúdo.

Nesse sentido, acredita-se que o levantamento acerca do uso da técnica de animação em stop motion como ferramenta no ensino é significativa. Dessa forma, este estudo de natureza básica, abordagem qualitativa, contém análises não generalizáveis pela estatística (Lakatos \& Marconi, 2007). Apresenta objetivos exploratórios e descritivos, pois, descreve a técnica de stop motion como ferramenta aplicada no ensino que instiga a percepção lúdica, sócio-educativa. Posteriormente, ao final, propõe diretrizes (Gil, 2008) no intuito de incentivar novos estudos e a aplicabilidade desta prática na educação.

\section{Design e as técnicas de animação}

Os designers expressam suas ideias por meio de técnicas que atendam aspectos como, entre outros, modularidade, abstração, estratificação, integridade, utilidade e beleza, aliando-os à uma proposta de projeto. A animação, enquanto atividade profissional, está relacionada ao planejamento e execução de um produto audiovisual. A atividade tem um campo de atuação bem diversificado, que contempla várias áreas de estudos, permitindo ao profissional trabalhar como autônomo ou em editoras, emissoras de TV, estúdios de cinema, produtoras de audiovisual publicitário institucional ou comercial, produtoras de conteúdo didático, produtoras de jogos digitais na área de animação, produtoras independentes, instituições de ensino na elaboração de materiais didáticos para a educação, além de agências de propaganda focadas no desenvolvimento de comunicação digital.

As áreas de estudos da animação, contemplam várias ferramentas e técnicas, que possuem diferentes níveis de complexidade e geram resultados estéticos diferentes. Algumas técnicas se destacam, como a animação tradicional, o stop motion e a animação 3D. A utilização de uma ou de outra vai depender do objetivo do trabalho. De acordo com Braga et al. 2015, essas técnicas são classificadas de acordo com a forma como as imagens são criadas, os materiais envolvidos e a tecnologia utilizada. A animação tradicional ou desenhada à mão é uma técnica utilizada na produção de muitos desenhos animados e filmes de longa-metragem feitos nos últimos 70 anos, o que é as vezes chamado de "animação cel." Esse termo refere-se às folhas de acetato transparente onde os diagramas são desenhados e fotografados no filme, a fim de que possam ser mostrados rapidamente, para criar a ilusão de movimento. Já a animação em stop-motion, consiste em tirar fotografias digitais fixas de objetos ou imagens depois de terem sido deslocados manualmente para simular o movimento. Por fim, a animação em 3D, essa é realizada por computador e as imagens são criadas digitalmente com o uso de uma grande variedade de técnicas e softwares.

Entre as técnicas expostas sabe-se que o stop motion tem sido utilizado como ferramenta voltada à educação e apresenta-se como uma alternativa promissora ao ensino, tendo em vista que alguns métodos tradicionais utilizados em sala de aula, objetivando a aprendizagem dos alunos, não atendem a esse objetivo e acabam desestimulando os mesmos, não despertando o seu interesse pelo conteúdo da disciplina. Portanto, importa a intervenção do design no desenvolvimento de sistemas que viabilizem conexões entre a técnica de stop motion e os conteúdos curriculares e também atendam as expectativas dos atores envolvidos no processo de ensino e aprendizagem. Assim, são importantes para a escola, os projetos que propõe a inserção de novas maneiras de aprender, incorporando-as aos trabalhados dos docentes, com vistas a motivar os alunos e fazer deles sujeitos atuantes na construção do próprio conhecimento.

\section{A técnica de animação em stop motion}


A história do stop motion remonta aos primórdios do cinema. Com o filme Viagem à Lua, 1902, o mágico e ilusionista francês George Mélies, usando a técnica de stop motion, deu sequência aos seus truques misteriosos e alcançou o ápice de sua carreira cinematográfica (BARBOSA, 2005). Ao longo do século $X X$, a técnica de stop motion foi sendo desenvolvida e aprimorada por diversos diretores de cinema e durante muito tempo foi a base para efeitos especiais em filmes com robôs e monstros, pois ainda não existia a tecnologia digital (PURVES, 2011).

Essa técnica foi utilizada em filmes de curta e longa-metragem como, Star Wars, do diretor George Lucas, que revolucionou o cinema com suas habilidades de efeitos especiais. Entre outros, que também utilizaram essa técnica, pode-se citar Tim Burton. Ele criou em 1982, Vincent, um curtametragem de terror para crianças. Outras animações em stop motion que se destacaram nos últimos anos foram: O Estranho Mundo de Jack, de Henry Selick e roteiro de Tim Burton (1993); a Fuga das Galinhas (2000), dirigido por Nick Park e Peter Lord; Wallace e Gromit (2005) de Steve Box e Nick Park; Coraline e o Mundo Secreto (2009) de Henry Selick; O Fantástico Sr. Raposo (2009), de Wes Anderson; além de A Festa do Monstro Maluco (1967); A Noiva Cadáver (2005) e Frankenweenie (2012), dirigidos respectivamente por Jules Bass, Henry Selick e Tim Burton. Verifica-se que a popularização dessa técnica ocorreu na década de 1990 (PURVES, 2011).

Em relação ao conceito e definição, o stop motion, que poderia ser traduzido como "movimento parado", é uma técnica que utiliza a disposição sequencial de fotografias diferentes de um mesmo objeto inanimado para simular o seu movimento (CIRIACO,2017; SOTT,2017 PURVES,2011; SHAW,2008). Estas fotografias são chamadas de quadros e normalmente são tiradas de um mesmo ponto, com o objeto, boneco ou desenho sendo manipulado manualmente, é isso que dá a ideia de movimento (PURVES,2011, SHAW,2008). Essa técnica oferece resultados satisfatórios, tanto como linguagem independente, quanto como efeito visual ou "truque" de filmagem (CIRIACO, 2017; SOTT, 2017). Porém, a realização eficiente dessa técnica vai depender de infraestrutura sólida, que permita, por exemplo, o controle da iluminação do ambiente, bem como a produção de efeitos de luz e sombra, e a estabilidade dos materiais utilizados (Purves, 2011; Shaw, 2008), além de equipamentos e habilidades, conforme Wells (2006), para construções manuais de cenários e bonecos e aplicação de técnicas de filmagem e fotografias live-action, termo utilizado no cinema, teatro e televisão para definir os trabalhos que são realizados por atores reais, distinguindose dos trabalhos animados.

O processo de produção da animação é dividido em três etapas: pré-produção, produção e pós-produção. Essas são descritas a seguir combinando as informações sobre o tema, conforme apresentado nos trabalhos desenvolvidos por Bossler, et al (2010), Kindem \& Musburger (1997), e Williams (2016), Purves (2011), e Shaw (2008).

\subsection{Pré-produção}

A etapa de pré-produção é a preparação do projeto, a parte criativa, que discorre sobre as mudanças ocorridas na confeç̧ão dos bonecos e cenários testes de materiais, etc., empregando em grande parte elementos físicos. Nesta etapa se realiza a experimentação técnica necessária para o desenvolvimento de novos recursos e ideias, por isso cada elemento deve ser bem planejado e projetado. $O$ quadro 1 apresenta seis passos para a elaboração da pré-produção. 
Quadro 1 - Passos da pré-produção.

\begin{tabular}{|c|c|}
\hline Passos da pré-produção & Descrição \\
\hline 1. Ideia & $\begin{array}{l}\text { Momento de definir se será uma série, curta ou } \\
\text { longa metragem, sua história e as possibilidades } \\
\text { narrativas e estéticas. }\end{array}$ \\
\hline 2. Story (história/guião) & $\begin{array}{l}\text { A ideia se consolida em uma história, onde deve } \\
\text { sair listagem de detalhes da animação para a } \\
\text { produção (sons, músicas, personagens, cenários } \\
\text { e objetos, animações e efeitos, etc). }\end{array}$ \\
\hline 3. Storyboard & $\begin{array}{l}\text { É a criação de sequência de imagens traduzindo } \\
\text { o guião para pré-visualização da animação. }\end{array}$ \\
\hline 4. Vozes e Som & $\begin{array}{l}\text { Importantes como guia de tempo nas etapas da } \\
\text { animação. As vozes e sons podem ser } \\
\text { melhorados em momentos posteriores da } \\
\text { produção. }\end{array}$ \\
\hline 5. Animatic & $\begin{array}{l}\text { União do storyboard com as vozes e sons } \\
\text { gravados para testar se a história funciona, com } \\
\text { seus tempos e pausas. }\end{array}$ \\
\hline 6. Design & $\begin{array}{l}\text { Momento do Concept Arts, desenvolvimento } \\
\text { visual dos personagens (proporções, poses, } \\
\text { aparência), Ambientes e objetos da cena e } \\
\text { estudo e definição dos esquemas de cores. }\end{array}$ \\
\hline
\end{tabular}

Fonte: adaptado de Bossler, et al (2010), Kindem \& Musburger (1997) e Williams (2016), Purves (2011), Shaw (2008).

\subsection{Produção}

Concluída a pré-produção, inicia-se a produção do filme, que efetivamente envolve os processos de filmagem e animação das cenas. Na produção se enfatiza a evolução técnica dos equipamentos de apoio e seus benefícios. O processo de produção consiste na captura da sequência de imagens do filme e emprega mais elementos físicos do que digitais, e ainda, depende da habilidade manual de profissionais como animadores, iluminadores e fotógrafos. 0 quadro 2 apresenta oito passos para elaboração da produção, conforme manual livre de animação (2017).

Quadro 2 - Passos da produção.

\begin{tabular}{ll}
\hline Passos da produção & Descrição \\
\hline 1. Layout & $\begin{array}{l}\text { Refinamento do storyboard, momento para } \\
\text { definir perspectivas, posicionamento e tempos. }\end{array}$ \\
\hline 2. Modelagem & $\begin{array}{l}\text { criação digital e física dos personagens, objetos e } \\
\text { cenários. Esses serão tocados pelo animador a } \\
\text { cada quadro da animação. }\end{array}$ \\
\hline
\end{tabular}




\section{Rigging}

5. Animação
Adição de controladores para animação dos personagens e demais objetos animáveis

Posicionamento e movimentação de personagens pela história, assim como da câmera e demais objetos.

\section{Efeitos especiais}

Utilização de sistema de partículas, como fogo, água, fumaça para efeitos na história.

Posicionamento e controle dos diversos tipos de luz necessários para cada cena. efeitos da iluminação que conferem vida aos personagens dando credibilidade à narrativa

Produção do material com vistas a finalização das imagens da animação.

Fonte: adaptado de Bossler, et al (2010), Kindem \& Musburger (1997) e Williams (2016), Purves (2011), Shaw (2008).

\subsection{Pós-produção}

Após a etapa de produção do filme, inicia-se o processo de pós-produção. Esse aborda o aprimoramento visual do filme, possibilitado pelas tecnologias digitais. Nesta fase, apesar de se manter o uso da técnica straight ahead (quando o animador desenvolve a animação quadro a quadro, ou seja, ele desenha o conteúdo do primeiro frame, depois desenha o segundo, depois o terceiro e assim por diante até o fim), e da aparente simplicidade do resultado final, observa-se nesta fase a predominância do uso dos processos digitais, tanto para o aprimoramento visual, quanto para superar os limites colocados pelo mundo físico, o que confere ao filme amplas possibilidades de realização. Além de permitir o acompanhamento em tempo real da evolução da captura das imagens, e assídua verificação do progresso, de forma a garantir a qualidade do resultado final. 0 quadro 3 apresenta cinco passos para elaboração da pós-produção, conforme manual livre de animação (2017).

Quadro 3 - Passos da pós-produção.

\begin{tabular}{ll}
\hline Etapa & Descrição \\
\hline 1. Composição & $\begin{array}{l}\text { Montagem de todos os objetos, } \\
\text { personagens, efeitos e animações da cena. }\end{array}$ \\
\hline 2. Correções & $\begin{array}{l}\text { Verificação das frames e correções e ajustes } \\
\text { finais }\end{array}$ \\
\hline 3. Títulos e efeitos finais 2D & $\begin{array}{l}\text { Criação de títulos, Motion graphics e outros } \\
\text { efeitos visuais finais }\end{array}$ \\
\hline 4. Correção de cor & $\begin{array}{l}\text { Etapa de edição do filme, tratamento das } \\
\text { cores com objetivo de } \\
\text { atingir a }\end{array}$ \\
\hline
\end{tabular}




\section{A técnica de animação em stop motion no ensino}

Com o desenvolvimento tecnológico e os cursos superiores de Animação, tanto a nível tecnológico como bacharelado, reconhecidos no Brasil pelo MEC, a cultura audiovisual vem ganhado destaque na educação das escolas, pois provocam fascínio nos alunos. Então, a utilização da produção audiovisual como um processo que possibilita o diálogo entre alunos e professores, é uma estratégia que, se investida pelo professor, poderá trazer contribuições à transmissão de qualquer conteúdo direcionado ao ensino fundamental e médio das escolas.

Nesse sentido, stop motion representa uma técnica cinematográfica, simples, de baixo custo, e nos remete a resultados satisfatórios tanto em questão de aprendizagem dos alunos, quanto ao interesse dos mesmos na produção de sua própria animação abordando o tema a ser aprendido. Além de que, os alunos estão sempre "presos" as mesmas práticas artísticas com relação ao cinema. Nesse contexto, o uso da técnica de animação com stop motion proporciona uma inovação em relação à prática do cinema nas escolas.

De acordo com Braga (et al. 2015), o stop motion é um tipo de recurso digital (vídeo) considerado como objeto didático pedagógico, quando utilizado para apoiar a aprendizagem. Segundo os autores, essa ferramenta pode ser uma grande aliada no processo educativo. Porém, é necessário, para isso, que o professor tenha clareza dos objetivos que deseja alcançar e, em seguida, pesquise, selecione e defina boas estratégias de utilização do objeto de aprendizagem, no caso o stop motion, em suas aulas, de forma a atender aos seus objetivos.

Sendo assim, a animação em stop motion, fundamentalmente, instiga à atuação pessoal do aprendiz, visto que proporciona o aprendizado de um modo mais ativo, facilitado pela compreensão das técnicas da animação. Além disso, este recurso didático permite a modelagem de eventos reais que evoluem temporalmente. Dessa forma, as animações interativas tornam-se ferramentas valiosas no auxílio daqueles alunos com alguma dificuldade de abstrair conceitos. Seu uso estimula processos cognitivos como percepção, memória, linguagem, pensamento e outros. Produzem ainda um ambiente lúdico para desenvolvimento da aula (BRAGA, et al, 2015).

O uso da técnica de animação no ensino e aprendizagem é antigo. Humberto Mauro, cineasta brasileiro, já observava em 1964, que a animação era um recurso educativo a ser explorado, pois, utilizando-se da linguagem de animação (stop motion) produziu o conhecido filme "A velha a fiar", com duração de 6 minutos, mostrando a ação de diversos animais em um dia a dia na fazenda. Em 1965, duas produções se destacaram, dirigidas por Chuck Jones, o curta metragem animado "The Dot and the line" e o média-metragem educativo "Donald in Mathmagic Land". O primeiro, conta a história de uma reta que se apaixona por um ponto, mas para que ela consiga conquistá-lo, ela precisa aprender a se expressar. Para isso, ela cria curvas e ângulos. Assim, vários elementos das disciplinas de Matemática são abordados no filme. Já o segundo, conhecido no Brasil como "Donald no país da Matemática", foi criado por Walt Disney. No filme, Donald, o famoso personagem de Walt Disney, se depara com um mundo gigantesco, cheio de elementos ligados à Matemática, principalmente à Geometria. 
Contudo, verifica-se que a maioria das escolas utilizam as animações apenas por entretenimento, e deixam de usar este recurso para ensinar conteúdo do programa das disciplinas oferecidos na escola. Assim, poucas iniciativas têm sido tomadas com o intuito de desenvolver roteiros, personagens e animações como apoio à educação, mostrando que o desenvolvimento de animações com caráter educacional tem se apresentado como um novo desafio para os produtores de conteúdo.

Porem existem festivais, como por exemplo o Anima Mundi, que é considerado o mais importante festival de animação que se realiza anualmente no Brasil e conta com profissionais de outros centros cinematográficos da Europa e da América do Norte para exibirem suas animações. Nesse evento são ministradas oficinas em que exploram as técnicas de animação, não só como meio de entretenimento, mas também como forma educativa, adotando uma linguagem voltada para a reflexão sobre a responsabilidade social, melhoria da qualidade de vida e sobre questões relacionadas ao meio ambiente (ANIMAMUNDI, 2017).

Ballesta (2012) demonstra a contribuição que a técnica de animação em stop motion, proporciona ao serviço da pedagogia com a finalidade didática, visando melhorar o processo de ensino e aprendizagem. $O$ autor atribui o aprendizado dos alunos usando essa técnica pelo fato que essa é áudio visual, pois $83 \%$ do aprendizado humano ocorre visualmente, $17 \%$ restante, pelos outros sentidos, nesse, $11 \%$ é pela audição. A técnica de animação em stop motion, em primeiro lugar parte de uma sucessão de imagens que junto com elementos sonoros resultam na produção audiovisual.

\subsection{Vivências em escolas: stop motion como ferramenta de ensino}

Ao utilizar o stop motion como ferramenta audiovisual com finalidades educacionais, os professores irão trabalhar com imagens e vídeos como elementos expressivos em um processo onde alunos vivenciarão o aprendizado mediante atitude ativa, colaborando com o processo de ensino e aprendizagem em um ambiente onde o professor atuará como viabilizador do processo, procurando uma aprendizagem integra e proporcionando novas questões que desperte o interesse e curiosidade dos alunos. Neste estudo foi levantado trabalhos que relatassem a aplicação dessa técnica em sala de aula.

De acordo com Barbosa (et al., 2012), a escolha das técnicas de animação deve levar em consideração, além da viabilidade tecnológica das escolas, a faixa etária das crianças, que no seu

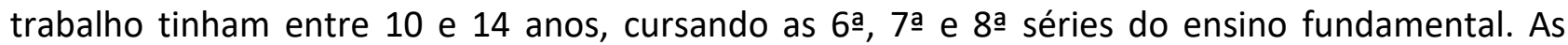
técnicas de animação escolhidas foram, a animação tradicional e o stop motion, por serem simples e práticas e não demandarem uma capacitação prolongada. Segundo os autores, após a aplicação das técnicas na disciplina de ciências, os professores e alunos afirmaram ter compreendido de forma clara as etapas necessárias no desenvolvimento das animações. Alguns professores colocaram que a aprendizagem é construída em todas estas etapas, contudo, é no desenvolvimento dos roteiros que se percebe maior necessidade de apropriação dos conhecimentos pelos alunos. Para os professores, a intervenção é significativa, não só na aprendizagem dos alunos, mas também na motivação dos mesmos nas aulas refletindo nas notas do ano letivo de 2012.

Santos (et al, 2016), descrevem a técnica stop motion e os resultados obtidos por meio desta em sala de aula. Os autores consideram a técnica como recurso didático pedagógico interdisciplinar tendo como principais etapas: enredo fílmico, elaboração de roteiro, cenários e personagens. A atividade foi realizada durante o 1 을 trimestre de 2016 nas aulas de Ciências e Arte, atendendo 35 
alunos do 9o período do ensino fundamental com o objetivo de relacionar o que se aprende do conteúdo (conhecimento científico) com o cotidiano do aluno e também perceber as conexões/relações existentes entre os conteúdos temáticos da disciplina de Arte (modelagem, fotografia, cinema) com os da disciplina de Ciências (forças e movimentos), estabelecendo a interdisciplinaridade no ensino e aprendizagem. Assim, os alunos conseguiram entender conceitos de forças e movimentos no contexto da Física (ensino de Ciências), mediante a técnica de stop motion, usando elementos como a fotografia, a modelagem, o cinema e a cor, conteúdo específico do ensino de Arte. Para os autores as aulas de Ciências e de Arte, auxiliadas por imagens (vídeo, cinema), permitiram aos alunos uma nova forma de construir e apropriar conhecimentos científicos, ao mesmo tempo em que possibilitou aos professores novos métodos de avaliação buscando sempre a melhoria na qualidade do ensino.

Santos (2015), relata que em um minicurso do Congresso Internacional de Educação Ambiental realizado na cidade de Murtosa em Portugal, no qual o objetivo foi evidenciar e promover debates sobre as atividades educacionais, e entre elas, foram mencionadas as produções de animação em stop motion com foco na valorização da cultura local das regiões de origem dos participantes e intuito de realizar atividades sobre os saberes ambientais em busca de uma sociedade sustentável. Segundo a autora a produção de animações foi muito importante, como uma potencial ferramenta que possibilitou diálogos, experiências e compartilhamento de saberes necessários para discutir e refletir criticamente sobre as relações socioambientais.

Nóbrega (2007), utilizou a técnica de animação em stop motion para o ensino de História com uma divisão puramente didática das etapas do trabalho, pois este teve variações no decorrer das experiências vivenciadas. Segundo o autor, conforme a turma, dinâmicas diferentes foram desenvolvidas. Então, nas quintas séries do Ensino Fundamental, as atividades envolveram a produção de histórias em quadrinhos sobre a lenda do guaraná, que foram essenciais para o entendimento de muitos aspectos do processo de trabalho com animação. Já com o segundo ano do Ensino Médio os alunos tinham que planejar cenas da revolução francesa e o enforcamento de Luiz XV. Quanto a aplicação da técnica, as etapas relativas à sessão de fotografia e à montagem, foram as mais estimulantes e vantajosas. Assim, de acordo com o autor não há possibilidade de engessamento do planejamento de trabalho com animação, porque turmas diversas assimilam diferentemente o que estão estudando e as dúvidas que vão surgindo não seguem um padrão prédefinido de trabalho.

Assim, verifica-se que a técnica de stop motion foi experimentada em diferentes áreas de conhecimento (história, matemática, biologia, artes, etc) e foi importante para o ensino e aprendizagem dos temas abordados. E, de acordo com o depoimento dos professores nos trabalhos referenciados, é nítido o interesse e envolvimento dos alunos nas atividades considerando todas as etapas de produção da animação.

\subsection{Vivências na IES: stop motion como ferramenta para replicar em escolas}

Elvins e Goulder (in: Purves, 2011), afirmam que um dos aspectos da animação é o uso como recurso para retratar visões inspiradoras ou educativas que outros meios podem ter dificuldades para comunicar. Portanto, a animação tem a capacidade de dar vida e significado a cenários, contextos diversos permitindo ao público pensar sobre um dado assunto de maneira diferente, pois esse recurso pode comunicar de forma rápida e lúdica qualquer conteúdo.

A animação, como indica os trabalhos citados, apresenta-se como uma nova forma de 
transferência de conteúdo nas escolas. Considerando esse contexto, torna-se uma ferramenta importante à inovação dos processos de ensino e aprendizagem, pois "a animação é mais do que personagens móveis; trata-se de narrativa, e cada elemento pode ajudar a contar essa história." (PURVES, 2011. p.135). Nesse sentido tem sido conduzida a disciplina de stop motion no curso de animação da UFSC (Universidade Federal de Santa Catarina). A motivação dos trabalhos realizados, segundo relato do professor orientador ${ }^{1}$ (viabilizador), foi a possibilidade de levar as técnicas de produção da animação em stop motion para além dos limites das Instituições de Ensino Superior (IES), considerando os níveis de graduação e pós-graduação, e dos estúdios (empresas), tendo como foco produtoras de animação e conteúdo.

Quanto ao desenvolvimento da referida disciplina, conforme entrevista, os alunos exploraram o tema "a horta: duendes $\mathrm{x}$ insetos" onde a horta apresenta-se como o ambiente e os personagens são duendes e insetos. Essa abordagem teve como objetivo integrar os alunos aos projetos do NASDesign ${ }^{2}$ com a temática de ressignificação dos espaços e subtemática: horta. Relacionando-as com a educação e sustentabilidade ambiental. A animação, em desenvolvimento, poderá resultar em material de divulgação sobre o projeto horta do NASDesign em fase de implantação no Campus Universitário (UFSC) visando motivar as pessoas a usarem a horta, tanto no sentido de coletar como plantar e também preservar os espaços.

No desenvolvimento do projeto de animação em stop motion considerou-se o entendimento das etapas: 1) pré-produção, 2) produção e 3) pós-produção. No entanto, sendo uma proposta interdisciplinar, a pós-produção ocorrerá em um projeto de extensão associado ao trabalho realizado, considerando os personagens e cenários finalizados nas etapas anteriores (ver figura 1). O entrevistado relata que na vivência da pré-produção os alunos fizeram planejamentos, cronograma, story (história/guião), storyboard, roteiro, animatic e concept arts. Já na produção, foram feitos layout, personagens, cenário e texturizações desses. Porém, os alunos não chegaram na etapa da fotografia (registros quadro a quadro), mas puderam ver como ocorre essa fase no estúdio de conteúdo e animação Animaking ${ }^{3}$.

Retomando a interdisciplinaridade do projeto de animação em stop motion ocorrido no curso da IES citada, o viabilizador (entrevistado) relata que o processo de produção ocorre em disciplinas diversas, a exemplo, o trabalho atual está relacionado aos conteúdos e práticas de disciplinas como, projeto I: base para projetos de animação, que envolve todos os aspectos da gestão da animação; Projeto II: animação em 2D, momento em que os alunos aprendem a usar

\footnotetext{
${ }^{1}$ Professor Pós-doutor Luiz Figueiredo, ministrante da disciplina stop motion do curso de animação (graduação), coordenador do programa de pós-graduação em design e do NAS Design (Núcleo de Abordagem Sistêmica), apoiado pela pós-graduação em Design da UFSC. Entrevista realizada no dia 28 de março de 2018.

${ }^{2}$ NASDesign é o Núcleo de Abordagem Sistêmica do Design, vinculado a Universidade Federal de Santa Catarina e fundado pelo Professor Pós-doutor Luiz Fernando Gonçalves de Figueiredo. É um núcleo que desenvolve Ensino, Pesquisa e Extensão na IES.

${ }^{3}$ A AnimaKing foi fundada em 2001 em São Paulo, por um designer e um profissional de marketing com objetivo de produzir conteúdo e animação para cinema e TV. Em 2013, segundo Paolo Conti (proprietário da empresa), destaca-se no mercado com a produção do primeiro longa-metragem de animação produzido mediante a técnica de stop motion. Essa foi distribuída pela FOX no Brasil e em mais de 30 países. Atualmente a empresa está instalada em Florianópolis, no Sapiens Parque e atualmente está desenvolvendo seu segundo longa-metragem e sua quarta série de animação que será exibida no Disney Channel. A AnimaKing é a única produtora de animação do sul do Brasil a participar do programa de núcleos criativos da Ancine.
} 
softwares e com a disciplina projeto III: animação em 3D. Nesse processo, a disciplina stop motion, serve de base para dar a percepção espacial do modelo tridimensional para a animação em 3D digital.

Figura 1 - Fluxo do desenvolvimento das etapas da animação

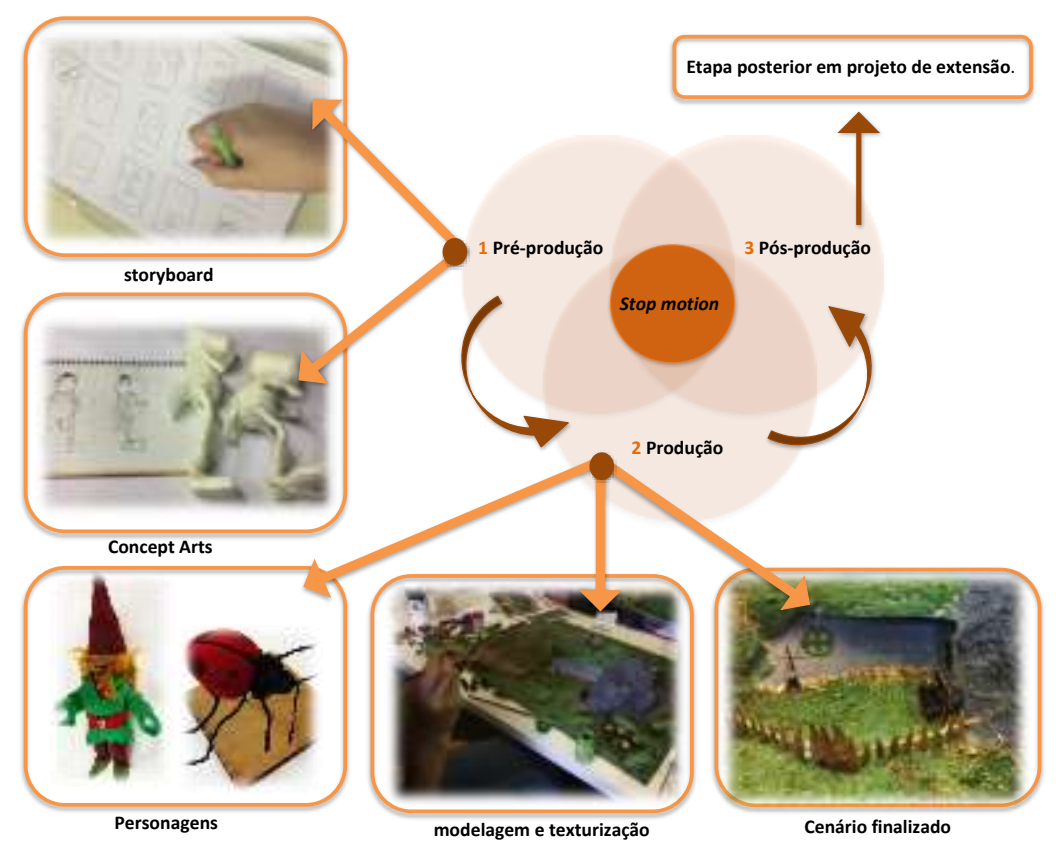

Fonte: desenvolvido pelos autores para pesquisa

Acrescenta-se que o projeto de animação em stop motion, orientado pelo professor entrevistado (2018) mantém parceria com a empresa de conteúdo e animação Animaking. Essa interação entre a empresa citada e a IES, representada pelo NASDesign, e apoiada pelo programa de pós-graduação em design da UFSC, ocorre mediante transferência de tecnologia e experiência em um processo de duas vias. A AnimaKing, no âmbito da prática empresarial e o NASDesign, no âmbito científico acadêmico. Na parceria, entre NASDesign e AnimaKing, conforme entrevista, há intensão de desenvolver modelos de prototipagem rápida e novos processos, produtos e sistemas para stop motion, com vistas na geração e transferência de conteúdo. Acrescenta-se que nesse interim, a AnimaKing tem a percepção de que precisa de recurso humano especializado para cumprir com todas as demandas que existem dentro da própria empresa e o NASDesign vem colaborar também com a formação de profissionais para entrar no mercado. Nesse sentido, em um sistema de interações e interlocuções envolvendo empresa, IES e escola, considerando nível fundamental e médio ou médio integrado, poderá ocorrer a fomentação da inovação de ferramentas que aprimorem o processo de ensino e aprendizagem dos conteúdos curriculares nas escolas (ver figura 2).

Figura 2 -Interações e interlocuções para inovação no conteúdo e ferramentas para educação. 


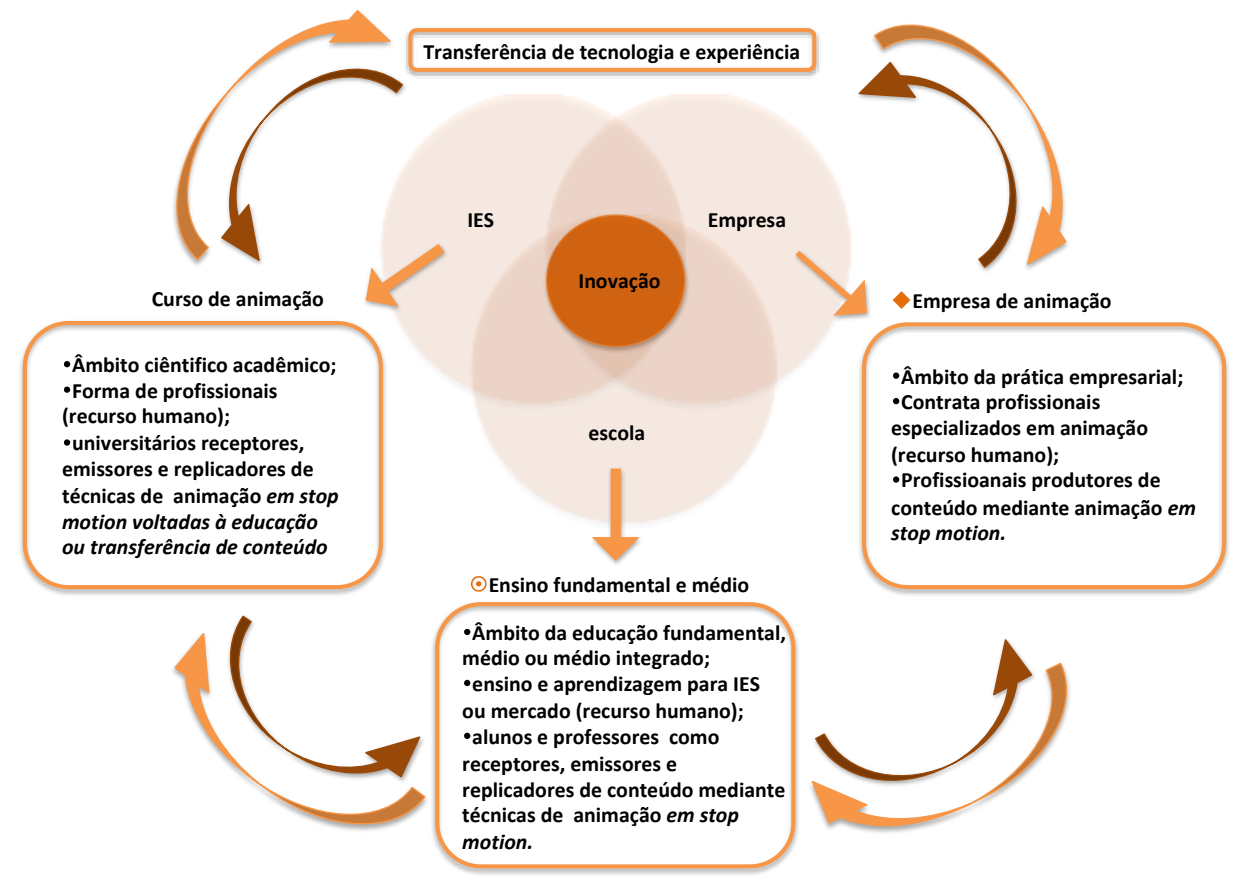

Fonte: desenvolvido pelos autores para pesquisa

Em entrevista, ao tratar sobre o trabalho, em desenvolvimento, e o benefício que esse poderá trazer às escolas públicas e privadas. $\mathrm{O}$ viabilizador do projeto afirma que o stop motion vem contribuir como forma de motivar alunos à criação de conteúdo, nesse sentido, essa técnica de animação pode ser um meio voltado ao processo de ensino e aprendizagem, de forma que esse ocorra em um ambiente inspirador e lúdico atraindo os alunos ao universo da pesquisa e motivando os professores a buscarem inovações na transferência de conteúdo e nos sistemas que fomentem maior conexão entre docentes e discentes. Segundo narrativas do professor, importa nesse projeto a aplicabilidade e replicabilidade do sistema de ensino e aprendizagem por meio das técnicas de produção de animação em stop motion nas escolas, sendo, os universitários, os professores e alunos das escolas receptores, emissores, replicadores e, consequentemente, viabilizadores da inovação (ver figura 2).

Quanto aos trabalhos futuros tendo em vista a parceria do núcleo de pesquisa com uma empresa de animação, conforme entrevista, vislumbra-se a inserção dos alunos de animação no mercado de trabalho e prospeç̧ão de novos negócios com foco na animação em stop motion e transferência de conteúdo como uma contribuição sociocultural envolvendo IES, empresa e escolas.

\section{Diretrizes para aplicabilidade da animação em stop motion na educação.}

Com base na fundamentação teórica, depoimentos dos autores acerca da aplicação de técnicas de animação em stop motion em escolas e experimentações realizadas por graduandos do curso de animação, auxiliados por alunos da pós-graduação em design, com a finalidade de replicar as técnicas de animação em stop motion no ambiente escolar, é possível delinear algumas diretrizes, com vistas na fomentação do uso dessa técnica como ferramenta voltada à educação. Desta forma pode-se afirmar que: 
- É mediante a adaptação e readaptação da atividade lúdica que se pode desenvolver um encaminhamento pedagógico capaz de romper obstáculos e buscar na produção de vídeos, usando a técnica do Stop Motion, alternativas para enfrentar os desafios do ensino. A dimensão significativa e motivadora na produção de um vídeo de animação é que essa linguagem é lúdica, permite brincar com a realidade, reinventar cenários históricos, reinterpretar o contexto estudado, reinseri-lo na leitura contemporânea dos estudantes (NÓBREGA, 2007).

- O processo de análise e/ou produção da linguagem audiovisual pode estimular operações cognitivas articuladas como memória, atenção, raciocínio e imaginação. As imagens em movimento provocam sensações e estimulam a percepção, intuímos e observamos, simultaneamente, a música, os sons, as cores, a disposição dos elementos dentro do quadro, as sugestões vindas do extracampo (SANTOS, et al, 2016).

- Na produção de vídeo, no caso da técnica de animação em stop motion, percebe-se, pelo relato na pesquisa bibliográfica, que uma quantidade significativa de conceitos sobre cada parte a ser feita vem à tona na interação dialógica que, necessariamente, é estabelecida entre os diversos sujeitos responsáveis pela produção. Cada sujeito poderá externar seus pensamentos e intenções de diversas maneiras, pelo texto escrito, pelo desenho, oralmente e, claro, na utilização das tecnologias de comunicação (NÓBREGA, 2007).

- Deve-se buscar sempre novas estratégias que permitirão ao aluno um melhor entendimento dos conteúdos. Essas metodologias atreladas às dinâmicas e a ludicidade em sala de aula, irão proporcionar uma aprendizagem mais divertida, prazerosa e significativa (SANTOS, et al, 2016).

- Os alunos envolvidos no processo de produção e montagem do filme de animação em stop motion são autores na medida em que se tornam conscientes daquilo que estavam fazendo, entenderam como, por que, onde, quando e para quem tal discurso estava sendo elaborado (SANTOS, et al, 2016).

\section{Considerações Finais}

Este estudo apresentou conceitos e projetos relativos à técnica de animação em stop motion, assim como formas de utilização dessa para intervir no processo de ensino e aprendizagem, visando contribuir na educação. Nesse levantamento, verificou-se que a escola geralmente se mantém distante de alguns processos de mudança e transformação mediante uso de novas técnicas, tanto pelo desconhecimento das vantagens propiciadas pelo emprego dessas, quanto pela dificuldade de adaptação do novo às metodologias didático-pedagógicas utilizadas. Assim, o interesse por explorar o emprego do stop motion na educação escolar em parceria com estudantes de IES (graduandos do curso de animação e pós-graduandos de design) e empresa (produtora de conteúdo e animação) consiste em mostrar as vantagens que essa técnica pode propiciar tanto para a formação dos alunos universitários, despertando-os para prática docência ou mercado, como para os alunos do ensino fundamental e médio, instigando-os ao ambiente universitário e perspectivas profissionais.

Além da vantagem de, no âmbito escolar, a animação em stop motion poder ser uma ferramenta de ensino e aprendizagem que permite a abordagem de qualquer tema do conteúdo 
curricular ou do cotidiano dos estudantes, fazendo com que eles trabalhem em grupo, elaborem roteiros e cenários. Esse estudo indicou que modificações nos métodos de aprendizagem, proporcionadas pelas técnicas de animação, como o stop motion, trazem à sala de aula uma forma inovadora de ensino e aprendizagem, saindo do convencional, que as vezes não atinge o objetivo, que é aprender o conteúdo da disciplina. No uso dessa técnica, os alunos sentem a necessidade de se apropriarem dos conteúdos, já que eles serão necessários para fundamentar e dar sentido ao produto final, que é a animação em stop motion. $E$, durante o processo, verifica-se que de forma natural, ocorre a absorção do conteúdo da disciplina, o que implicará em uma aprendizagem aprazível e eficiente. Desta forma, os alunos deixam a condição passiva na sala de aula, tornandose elaboradores do conteúdo.

De maneira geral, com base na pesquisa bibliográfica abordada neste artigo, observa-se que os autores estão de comum acordo quanto a utilização da técnica de animação em stop motion como estratégia pedagógica eficiente, visto que pode ultrapassa fronteiras, de modo a auxiliar professores na aplicação dessa ferramenta em sala de aula e favorecer a motivação que necessita estar presente no processo de ensino e aprendizado. Acrescenta-se que em todos os trabalhos pesquisados, considerando diversas áreas de aplicação, o uso dessa técnica foi considerado satisfatório.

Assim, conclui-se que o stop motion pode ser uma ferramenta de ensino perfeitamente aplicável e eficiente à formação escolar e profissional, pois, com base no estudo, traz benefícios ao processo de ensino e aprendizagem nos seus diversos níveis. Neste estudo abordou-se em especial a aplicabilidade nas escolas públicas ou particulares de ensino fundamental e médio (inclui-se nesse grupo o ensino médio integrado à formação profissional técnica) e foi observado que o emprego da técnica de animação pesquisada apresenta muitas vantagens como, gerar aprimoramentos tanto de estudantes como de professores e pesquisadores ao possibilitar a aquisição de novos conhecimentos e a renovação de conceitos; instigar o trabalho em equipe; proporcionar a difusão do saber, promover o desenvolvimento sociocultural e a associação do saberes advindos da academia, escolas e empresas. Por fim, como estudos futuros pretende-se aplicar as experimentações realizadas pelos alunos da IES em escolas de municípios de Santa Catarina adequando às atividades de ensino as etapas descritas neste artigo: pré-produção, produção e pósprodução. Enfatizar-se que esses estudos e experimentações estão ainda em desenvolvimento envolvendo novas turmas no projeto aqui mencionado.

\section{Referências}

ANIMAMUNDI. Disponível em: <http://www.animamundi.com.br/en/>. Acesso em: junho, 2017.

BALLESTA, A.R. El uso del stop motion como médio para potenciar y desarrollar las capacidades del alumnado. Trabajo fin de Master.Universidad Internacional de la Rioja, Facultad de Educacion. Valencia, 2012.

BARBOSA JÚNIOR, A. L. Arte da Animação - Técnica e Estética através da história. Senac. São Paulo: 2005.

BARBOSA, M. C.; SANTOS P. H. dos; ALCOFORADO, M. G.; SARTORE, A. R. Educando com design de animação: uma metodologia de ensino e aprendizagem. InfoDesign Revista Brasileira de Design da Informação. São Paulo, v. 9, n. 1, p. 21 - 32, 2012. 
BOSSLER, A. P.; LOPES, G.; NASCIMENTO, S. S. Territórios de Interlocução: Animações, FaE/UFMGCECIMIG. Belo Horizonte: 2010.

BRAGA, J. (Org.). Objetos de Aprendizagem, UFABC. Santo André: 2015. Disponível em: <pesquisa.ufabc.edu.br/intera/?page_id=370 >.Acesso em: maio, 2017.

CIRIACO, D. $O$ que é o stop Motion? Disponível em:

http://www.baixaki.com.br/info/2247-o-que-e-stop-motion-.htm. Acesso em: junho 2017.

GIL, A. C. Métodos e técnicas de pesquisa social. Atlas. São Paulo: 2008.

KINDEM, G.; MUSBURGER, R. B. Introduction to Media Production: from analog to digital, Focal Press, Bostom: 1997.

LAKATOS, E.M.; MARCONI, M.A. Metodologia Cientifica, Atlas. São Paulo: 2007.

PURVES, B. Stop Motion. Bookman, Porto Alegre: 2011.

NOBREGA, D. S. Animação quadro a quadro: Uma experiência didática no ensino de história. Dissertação apresentada ao Programa de Pós-graduação em Educação da UNESP. Marília-SP, 123p. 2007.

SANTOS, J. N. dos; ROCHA, L.; GEBARA M., J., F. Stop motion: comunicação visual como recurso didático pedagógico nas aulas de ciências e arte. Revista da SBEnBio. VI Enebio e VIII Erebio Regional 3. n. 9, p. 1156 - 1167, 2016.

SANTOS, T.F.dos. Produção de animações como ferramenta para discutir a questão ambiental: uma vivência lusófona. REVISEA - Revista Sergipana de Educação Ambiental. São Cristóvão-SE, v. 1, n.2, 2015

SHAW, S. Stop Motion:Craft Skills for Model Animation, Focal Press. New York: 2008.

SOTT, A. Stop Motion. Disponível em: <http://www.stopmotionanimation.com/>. Acesso em: junho 2017.

WELLS, P. Fundamentals of Animation, AVA Publishing. Londres: 2006.

WILLIAMS, R., Manual de Animação, Senac. São Paulo:2016. 